Running Head: MEASURING DISPARITIES IN CHILD WELFARE

New Methodology: Measuring Racial or Ethnic Disparities in Child Welfare

\author{
Corresponding Author \\ Nancy Rolock \\ Jane Addams College of Social Work \\ University of Illinois at Chicago \\ 1040 W. Harrison Street (M/C 309) \\ Chicago, Illinois 60607-7134 \\ E-mail: rolock@uic.edu \\ Phone: (312) 413-2307
}

Fax: 312-996-2770

\title{
Acknowledgments
}

The author would like to acknowledge the assistance of Dr. Mark F. Testa, Dr. Robert B. Hill, and Dr. Alan J. Dettlaff for comments on previous drafts of this paper, and the Illinois Department of Children and Family Services, Erwin McEwen, Director, for partial funding of this study. 


\begin{abstract}
Understanding the disparate treatment of African American children in the child welfare system requires consideration of the dynamics at a community level and the state level. Looking across a state allows one to target policies and practices to areas within the state that are most in need. This paper argues for a new method of assessing disparate treatment in child welfare that takes into consideration the racial or ethnic makeup of the community in conjunction with the racial or ethnic makeup across the state. This paper uses decision based enumeration which helps to pinpoint decisions where disparities are the greatest, and helps target decisions that most impact disparate treatment. This paper utilizes a methodology that is both accessible to state and county child welfare administrators and utilizes data that is readily available to child welfare policy makers and administrators. Using data from Illinois to illustrate this methodology, this paper highlights the regions within the state where limited resources may be targeted to address disproportionate representation and disparate treatment in Illinois’ child welfare system.

Key words: Child welfare; racial or ethnic disparity; over representation; disproportionality; disparity; foster care outcomes
\end{abstract}


New Methodology: Measuring Racial or Ethnic Disparities in Child Welfare

While there has been much attention given to the disproportionate representation of children of color in the child welfare system, and there has been considerable effort made to clarify the difference between disproportionality and disparity, there is less clarity in how to measure these concepts. Typically disproportionality and disparity are discussed in child welfare in terms of the composition of the child welfare population, a risk ratio, or a disparity or disproportionality index (Needell et al., 2010; Shaw, Putnam-Hornstein, Magruder, Needell, 2008; Wulczyn \& Lery, 2007; Wulczyn, Lery \& Haight, 2006). This study argues for the adoption of a weighted risk ratio to measure disparate treatment of children in foster care. When the racial or ethnic composition of communities vary substantially within a single state, a risk ratio or disparity index which focuses on the risk of one group compared to another group in that community, is difficult to compare across communities within the same state. A weighted risk ratio addresses this limitation by standardizing the demographic distribution of a community to match that of the state to which the community belongs (Bollmer, Bethel, Garrison-Mogren \& Brauen, 2007). Because a weighted risk ratio accounts for variance in the size of the ethnic groups in each community, it allows comparison across communities within the state. This paper uses data from Illinois to illustrate the utility of a weighted risk ratio.

A second measurement issue that emerges is the difference between population enumeration and decision based enumeration. Discussed in more detail later in this paper, a population based enumeration compares, for instance, the racial makeup of children who enter foster care in a state to all children living in the state. By contrast, decision based enumeration compares the makeup of children who enter foster care to the children at risk of entering foster 
care due to be the preceding decision-point in the sequence of service delivery, rather than all children in the population. This study argues for the use of decision based enumeration.

\section{Problem Definition}

Research shows that in the United States African American children are represented in the child welfare system at a rate considerably higher than their percentage in the general population (Hill, 2005). In 2009, African American children made up 15\% of the child population, $24 \%$ of maltreatment victims, $26 \%$ of foster care entries, and $31 \%$ of children in foster care (see Figure 1) (USDHHS, 2010). According to the Administration for Children and Families, "the percentage of Black (non-Hispanic) children entering foster care was substantially larger than the percentage of these children in the State population in all but four States” (USDHHS, 2005). Given the higher rates of African American involvement in child welfare systems nationally compared to children of other races or ethnicities, there has been much focus on this overrepresentation in recent years (Derezotes, Poertner, \& Testa, 2005; Hill, 2007; United States General Accounting Office, 2007). 


\section{Figure 1. U. S. Child Welfare System 2009}

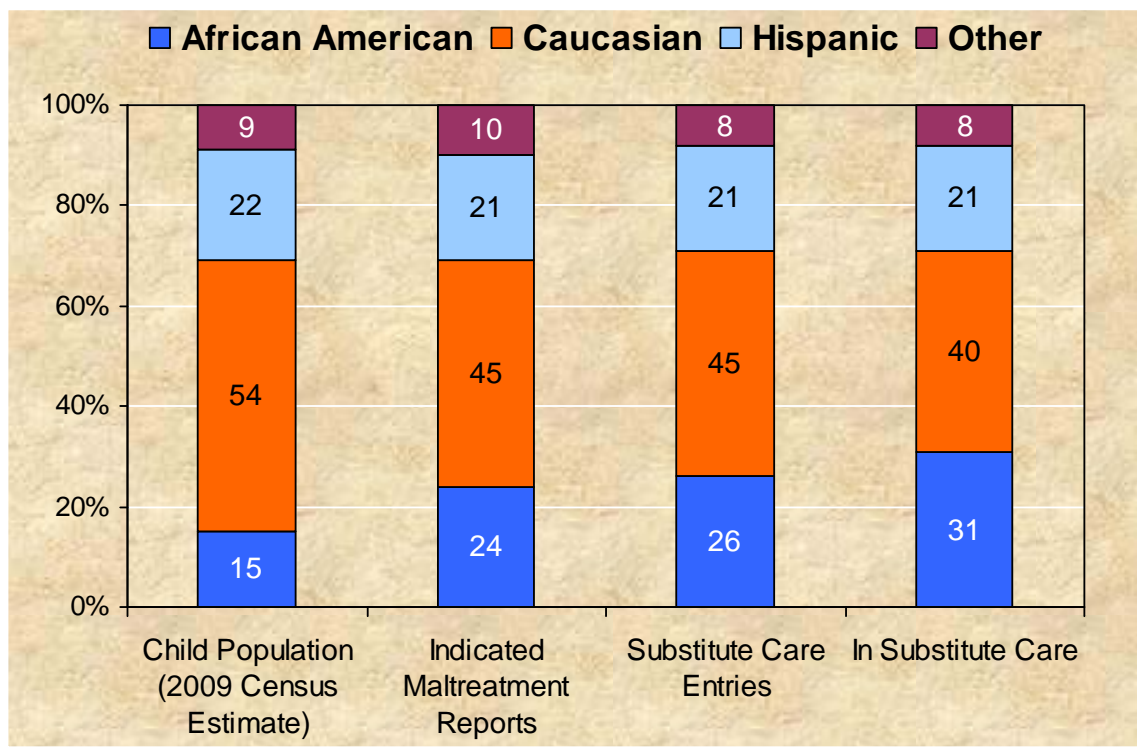

Figure 1. U. S. Child Welfare System 2009. The racial composition of children in the United States, (U. S. Census Bureau, 2009), column 1, is compared to the racial composition of children involved with the child welfare systems nationally at various stages: subjects of indicated maltreatment reports (column 2), those entering foster care (column 3), foster care population (column 4), and exits from care (column 5) (USDHHS, 2010).

Within the child welfare system, this overrepresentation has been referred to disproportionality, defined as "differences in the percentage of children of a certain racial or ethnic group in the country as compared to the percentage of the children of the same group in the child welfare system” (Hill, 2006, p. 3). Thus, the comparison between the percentage of African American children who make up the child population in the United States (15\%) to the percentage of maltreatment victims who are African American (24\%) is an example of disproportionality. While disproportionality refers to the state of being out of proportion, disparity refers to a state of being unequal when compared to children of other races. As defined by Hill (2006, pg. 3), “Disparity means unequal treatment when comparing a racial or ethnic minority to a non-minority. This can be observed in many forms including decision points (e.g., 
reporting, investigation, substantiation, foster care placement, exit), treatment, services, or resources.” Ultimately, disparities that occur in both entries to the system and exits from the system produce disproportionality (Chapin Hall Center for Children, 2008). Thus, identifying and responding to disparities are essential in reducing disproportionality.

One issue that clouds this discussion is that there is no clear standard for child welfare involvement. One cannot say, for instance, that because less than $1 \%$ of children in the United States are in foster care that this is the correct percentage - nor is there any evidence that this percentage should necessarily be higher or lower. While it is often assumed that less contact with the child welfare system is good, both under and over representation of specific ethnic or racial groups should raise questions (Lu et al, 2004; Shaw, Putnam-Hornstein, Magruder \& Needell, 2008). In addition, there is no consensus in the field that the attention paid to this issue is warranted, suggesting that children and families of color have different risk factors and therefore different needs, and it is these differences which account for the overrepresentation of children of color (Bartholet, 2009). Yet despite this lack of consensus, what is clear from current research is that once African American children and families come to the attention of the child welfare system they experience disparate treatment: African American children enter foster care at higher rates than other groups, and once in care African American children stay longer than children of other races or ethnicities.

This paper will address measuring the disparate treatment of children involved with the child welfare system. To that end, this paper builds on work done in education to assess disparities in education (Bollmer, Bethel, Garrison-Mogren \& Brauen, 2007) and introduces child welfare to a new measure to examine racial disparities. This new measure, a weighted risk ratio, takes into consideration the racial or ethnic makeup of the community in conjunction with 
the racial or ethnic makeup across the state; using a weighted ratio allows for a more accurate comparison when examining disparities within a state child welfare system. Previous methods have held the experiences of Caucasian children as the standard by which all other children should be compared. This paper argues that the children of interest (e.g., African American children) should be compared to all other (e.g., non-African American) children.

\section{Measurement Issues}

A discussion of disparate treatment of African American children in the child welfare system is complex and is most likely a result of numerous factors. While there seems to be general concern about the issue of disparate treatment of African American children, there is no clear understanding of why it occurs, what to do about it, or how to measure it. Key measurement issues are considered in this section: the preference for a weighted risk ratio, the choice of a reference group when calculating risk ratios, and the choice of a denominator in selecting a population based or decision based enumeration.

\subsection{Weighted Risk Ratio}

Understanding disparate treatment requires consideration of the dynamics at a local level; the racial composition in communities may impact how minority children are treated (Coulton, Crampton, Irwin, Spilsbury, \& Korbin , 2007; Drake, Lee, \& Jonson-Reid, 2009; Roberts, 2007; Barth, 2005; Wulczyn \& Lery, 2007; US GAO, 2007). Understanding disparities at a local level within a state allows child welfare staff and administrators to target policies and practices to areas that are most in need. A logical first step in understanding disparities is an effective measure that assesses where disparities occur both at a state level and at a community level, as only then can the issue be fully understood and potential solutions developed. In this analysis we focus on the regional level, but the same methodology could be applied to smaller communities. 
Currently a risk ratio, sometimes referred to as a disparity index, is often used to look at child welfare disparities (Center for the Study of Social Policy; Shaw, Putnam-Hornstein, Magruder, Needell, 2008; Wulczyn \& Lery, 2007; Wulczyn, Lery \& Haight, 2006). The strength of the risk ratio is that it is fairly easy to interpret, and "the risk ratio provides a unitless measure that can be evaluated without reference to other data” (Bollmer, Bethel, Garrison-Mogren, \& Brauen, 2007, p. 187). However, when communities vary substantially in terms of their racial or ethnic composition, the risk ratio is limited. In comparing data from two communities where African American children achieve an outcome at the same rate, their weighted risk ratios are the same in both communities. However, as data from Illinois will illustrate, a standard risk ratio is higher in a community with a large percentage of African American children and smaller in a community with a smaller percentage of African American children, despite the risk being the same for African American children in both communities. By standardizing according to the population of the state, a weighted risk ratio provides community-level data that can be used to compare disparities across the state.

Finally, the data that are used to examine disparities in this study, similar to the work done in California by the Center for Social Services Research and elsewhere (Shaw, PutnamHornstein, Magruder, Needell, 2008), is information that is readily available to most staff involved with child welfare systems. Armed with the racial makeup of the community, the cohort of children investigated for maltreatment, as well as those who enter and exit foster care, anyone can use this methodology to assess over and under representation in their community. This methodology is borrowed from the field of education where researchers have posted worksheets online where school districts can input data and look at over or under representation 
in their school districts (Data Accountability Center). The same can be done with this methodology.

\subsection{Choosing a Reference Group}

Another methodological issue is choosing a reference group. With risk ratios one compares a single race/ethnicity with another -- there is often a comparison made between outcomes for African American children compared to outcomes for Caucasian children, or children of Hispanic ethnicity to non-Hispanic White children. Sometimes, there is a comparison made between one race and all other races, rather than a single race. This paper argues for the use of all other races as a comparison group. Using all other races allows comparable ratios to be calculated for all racial or ethnic groups, and to be calculated in the same manner for all racial or ethnic groups. "Furthermore, risk ratios can be calculated in states or districts with diverse racial/ethnic distributions, including those with homogenous distributions and those without a clear racial/ethnic majority” (Bollmer, Bethel, Garrison-Mogren, \& Brauen, 2007). Finally, in utilizing all other children as the comparison group there is no longer a single race (usually Caucasian) that is used as a standard by which other groups are compared.

\subsection{Choosing a Denominator}

Another key methodological consideration in looking at disproportionality is a decision to use population based or decision based enumeration. Population enumeration requires the researcher to use the entire population of children in a community as the denominator while decision based enumeration uses only those children at risk for the event in the denominator. A population based study, for instance, compares children who enter foster care to all children in the community. This provides a general understanding of the degree of over- or underrepresentation of a particular racial group in the foster care population at various stages of child 
welfare involvement, but does not address disparate treatment. It has general appeal in that it is readily understood; reporting the level of maltreatment investigation in relationship to the proportion of children in the community makes sense as this assesses the response of the community in reporting alleged maltreatment (Fluke, Yuan, Hedderson, \& Curtis, 2003). However, once beyond the initial maltreatment report, subsequent decisions are made based on which children were referred to the child welfare system; generally families that do not come to the attention of the child welfare system are not at risk of placement into foster care. Another limitation of the population enumeration approach is that the impact of the rate of reporting of maltreatment is considered when assessing differences by race at each subsequent decision point. This study argues for a decision based approach where the comparison population (the denominator) is the group of children who make up the risk population. For instance, children entering foster care are compared to the children at risk of entering foster care due to the preceding decision-point in the sequence of service delivery, not all children living in the community, since the vast majority of the children living in the community are not at risk of entry into foster care. This study follows significant decision points that impact a child's time in foster care. With each new calculation the underlying risk population changes to reflect who is at risk for a specific outcome.

\section{Decision Point Considerations}

Decision based enumeration can take many forms, and not all children follow the same path in or through child welfare; a younger sibling, for instance, may be removed from her home without a formal maltreatment investigation. While child welfare systems vary in terms of how decisions are made and who makes decisions related to suspected cases of child maltreatment, a general trajectory of decisions includes an initial report that brings children to the attention of the 
system, acceptance of reports for investigation, a decision to provide services to a family either through in home services or entry into substitute care, for those children who enter foster care, placement decisions while in care, and ultimately exits from care. For this study, the decision based enumeration will be a series of decisions which account for major decisions for children and families involved in the Illinois child welfare system.

Using a decision based approach, this study outlines a series of decisions that are typically made for children who are subjects of maltreatment reports. As the focus of this paper is the methodology for measuring disparity, this study is limited to four decision points where administrative data are readily available. As data on the reports made to Illinois' child welfare system is limited, the first decision point with available data is the rate at which investigations occur in relationship to the proportion of children who live in Illinois. Once an investigation occurs, a decision is made regarding the level of services to be provided to the family. For some children and their families, a decision is made that no further child welfare involvement is necessary, and for others there is a decision to provide services, either services in the home without the child being removed or foster care services where children are removed from their homes. This study examines disparity for children who are investigated, the rate at which children are referred for intact family (or in-home) services and the rate at which children are placed in foster care. Finally, for children who are placed in foster care, this study examines the likelihood of long term foster care, defined as children in care for at least three years without an exit to a permanent placement through reunification, adoption or subsidized guardianship.

The decision-based enumeration used in this study omits some critical decision points; a more thorough analysis may have included, for instance, all incidents of maltreatment that result in maltreatment reports, and which reports are screened in and investigated. However Illinois 
does not collect detailed data on reports of maltreatment which are screened out prior to an investigation. With current available data it is difficult to discern if the disparities that are highlighted at the point of investigation are similar to those that occur at the point when a decision is made to report maltreatment. As the discussion of decision-based enumeration versus the population-based enumeration continues, consideration needs to be given to which decision points are included.

Another limitation of decision-based enumeration is that, while this methodology is described as if each decision is a set of nested decisions, the reality of child welfare does not lend itself to such distinct categories. In Illinois, for instance, $10 \%$ of the children removed after an investigation in 2007 did not have a substantiated maltreatment report, and 27\% of the children who received in-home services did not have a substantiated maltreatment report. This could be due to a child being removed from their home because there is a substantiated maltreatment report on another child in the home, or because there are safety concerns in the home that do not warrant a substantiated report. In this study, the children who were investigated for maltreatment are followed, and the decision around the level of service provided is used as the next decision point.

\section{Methodological Considerations}

Disparity can be evaluated through a variety of methods - each one taking a slightly different approach to answering the same question: is the likelihood that one racial/ethnic group will experience an outcome greater or less than the likelihood for other racial/ethnic groups?

Figure 1 shows the composition of US child population and of children involved with the foster care system. From this data a risk ratio, also known as a disparity index, is calculated to measure the likelihood that children from a particular ethnic/racial group will experience an outcome - for 
instance, the likelihood that once investigated for maltreatment, African American children will enter foster care. This likelihood is then compared to the likelihood of another group attaining the same outcome. With the large numbers associated with national or state level data, the risk ratio works well, but often there is a need to delve deeper to understand regional differences in representation because the racial makeup varies throughout the state. In regional analysis, however, some populations are so small that risk ratio calculations become difficult, or impossible to make.

A risk ratio compares the risk of a targeted population with the risk of all other children, or to a specific racial group. Data from Illinois will be used to illustrate the difference between a risk ratio and a weighted risk ratio. For the purpose of this illustration, a risk ratio that compares one race to all other races will be discussed as this is the calculation used in a weighted risk ratio. Risk ratio is influenced not only by the racial composition of the population in question, but also of the comparison group. When the racial composition of a population varies from community to community, a weighted risk ratio allows for comparison across communities within a state, while a risk ratio falls short in this endeavor (see Table 1 for the calculation). A racial group may have the same risk ratio in two communities, but very different risk ratios because of the variability in the community-level racial distributions. A weighted risk ratio, however, allows for comparisons within a state.

\section{Table 1}

Calculation of a Weighted Risk Ratio for African Americans

((1-state \% of African Americans with this outcome) * Regional \% of African Americans with this outcome)

((State \% of Caucasians with this outcome* Regional \% of Caucasians with this outcome) + 
(State \% of Hispanics with this outcome * Regional \% of Hispanic with this outcome) + (State \% of Other races with this outcome * Regional \% of Other races with this outcome))

The weighted risk ratio standardizes the racial distribution of a community to match that of the state, thus allowing states to discern where the greatest disparity exists within a state and target resources accordingly. The weighted risk ratio uses regional level risk ratio for the racial group in question (in the numerator) and a weighted risk ratio of all other children (minus the target group) in the denominator. It is suggested that the alternate risk ratio be used when fewer than 10 children of a specific racial group experience the outcome, or less than 10 children of the racial group have entered foster care (see Table 2 for the formula) (Bollmer, Bethel, GarrisonMogren, \& Brauen, 2007).

\section{Table 2}

Calculation of an Alternate Risk Ratio for African Americans

(African American children who experienced the outcome in region $\div$ African American children in the region) $\div$ (All other children who experienced the outcome in the state $\div$ All other children in the state)

The biggest difference between a risk ratio and a weighted risk ratio is that the latter is weighted to consider the racial makeup of the entire state. For this analysis, the data is examined by region - these regions represent the division of child welfare in Illinois - Cook County, Northern, Central and Southern, and vary quite substantially in terms of the racial/ethnic makeup of the population (see Table 3). For instance, in Cook County, the largest urban area in the state, the racial makeup of the child population is fairly evenly split - 29\% African American, 32\% Hispanic, and 33\% Caucasian. Yet, 56\% of investigated maltreatment reports involve African American children, 75\% of children who enter care are African American, and 75\% of children 
in long term foster care are African American. The region of the state with the smallest percentage of African American children is the Northern region - 8\% of the children in this region are African American, yet they comprise 25\% of investigated maltreatment reports, 39\% of foster care entries, and $47 \%$ of children in long term foster care.

\begin{tabular}{|c|c|c|c|c|c|c|}
\hline \multirow{5}{*}{$\begin{array}{l}\text { Region } \\
\text { Northern }\end{array}$} & Race/Ethnicity & $\begin{array}{l}\text { Child } \\
\text { Population } \\
\text { (Census } \\
\text { 2009) }\end{array}$ & $\begin{array}{l}\text { Investigated } \\
\text { Maltreatment } \\
\text { Reports }\end{array}$ & $\begin{array}{l}\text { Intact } \\
\text { Family } \\
\text { Cases }\end{array}$ & $\begin{array}{l}\text { Foster } \\
\text { Care } \\
\text { Entries }\end{array}$ & $\begin{array}{l}\text { Long } \\
\text { Term } \\
\text { Foster } \\
\text { Care }\end{array}$ \\
\hline & African & & & & & \\
\hline & American & $8 \%$ & $25 \%$ & $24 \%$ & $39 \%$ & $47 \%$ \\
\hline & Hispanic & $20 \%$ & $11 \%$ & $12 \%$ & $9 \%$ & $4 \%$ \\
\hline & Other & $7 \%$ & $4 \%$ & $3 \%$ & $3 \%$ & $2 \%$ \\
\hline \multirow{4}{*}{ Central } & Caucasian & $65 \%$ & $60 \%$ & $61 \%$ & $49 \%$ & $47 \%$ \\
\hline & African & & & & & \\
\hline & American & $9 \%$ & $22 \%$ & $20 \%$ & $38 \%$ & $42 \%$ \\
\hline & Hispanic & $11 \%$ & $2 \%$ & $2 \%$ & $3 \%$ & $1 \%$ \\
\hline \multirow{5}{*}{ Southern } & Other & $6 \%$ & $3 \%$ & $2 \%$ & $2 \%$ & $2 \%$ \\
\hline & Caucasian & $74 \%$ & $73 \%$ & $76 \%$ & $58 \%$ & $55 \%$ \\
\hline & African & & & & & \\
\hline & American & $15 \%$ & $24 \%$ & $21 \%$ & $29 \%$ & $34 \%$ \\
\hline & Hispanic & $3 \%$ & $1 \%$ & $1 \%$ & $1 \%$ & $1 \%$ \\
\hline \multirow{7}{*}{ Cook } & Other & $3 \%$ & $2 \%$ & $1 \%$ & $1 \%$ & $1 \%$ \\
\hline & Caucasian & $79 \%$ & $73 \%$ & $77 \%$ & $68 \%$ & $64 \%$ \\
\hline & African & & & & & \\
\hline & American & $29 \%$ & $56 \%$ & $55 \%$ & $75 \%$ & $75 \%$ \\
\hline & Hispanic & $32 \%$ & $15 \%$ & $17 \%$ & $10 \%$ & $10 \%$ \\
\hline & Other & $7 \%$ & $5 \%$ & $5 \%$ & $1 \%$ & $1 \%$ \\
\hline & Caucasian & $33 \%$ & $25 \%$ & $23 \%$ & $14 \%$ & $14 \%$ \\
\hline
\end{tabular}

To illustrate the difference between a risk ratio and a weighted risk ratio this illustration will assume that there is no regional variation in these racial groups. We therefore assume that all children have the same risk ratio of being the subject of an investigated maltreatment report in each community in the state as they do in the state as a whole - that is the risk ratio for African American children is 2.49, for Caucasian children is 0.94 , and for children of Hispanic ethnicity 
is 0.33. If African American children are 2.49 times as likely to be subjects of a maltreatment report in any community then one would expect the risk ratio to be same in every community, regardless of the size of the African American population. Once calculated, however, the risk ratio for African American children in Cook County (where African American children make up $29 \%$ of the population) is 3.13 and in the Southern region (where African American children are only $15 \%$ of the population) it is 2.53 . A weighted risk ratio, by contrast, is 2.86 in both locations - African American children are 2.86 times as likely as all other children to be subjects of an investigation of maltreatment in both Cook and Southern - and anywhere else in the state.

The reason these two calculations show different results is that a risk ratio is influenced by the fact that African American children make up less of the population in the Southern region than they do in Cook - the risk ratio over-estimates the disparity in Cook where African American children make up a larger percent of the population and under-estimates the disparity in the Southern region where African American children make up a smaller percentage of the population. By standardizing according to the population of the state, as done with the weighted risk ratio, one arrives at community-level data that is comparable across the entire state and one can compare outcomes in one community with the outcomes of a neighboring community.

\section{Application of the Weighted Risk Ratio}

To illustrate how a weighted risk ratio is used at a state level to assess disparity, the weighted risk ratio was applied to administrative data from Illinois for state fiscal year 2010 using a decision-based enumeration. As shown in Figure 2, across all DCFS regions, African American children are more likely to be investigated for maltreatment than any other group of children in the state. In the Northern region, African American children are 3.92 times more likely to have a maltreatment investigation than any other children in the state. African 
American children in the Central region are 3.29 times more likely, 2.91 times more likely in Cook County, and 2.09 times as likely in the Southern region. Caucasian and Hispanic children in all regions are less likely to be investigated for maltreatment.

Figure 2. Of all Children in the Region, the Weighted Risk Ratio of an Investigated Maltreatment Report

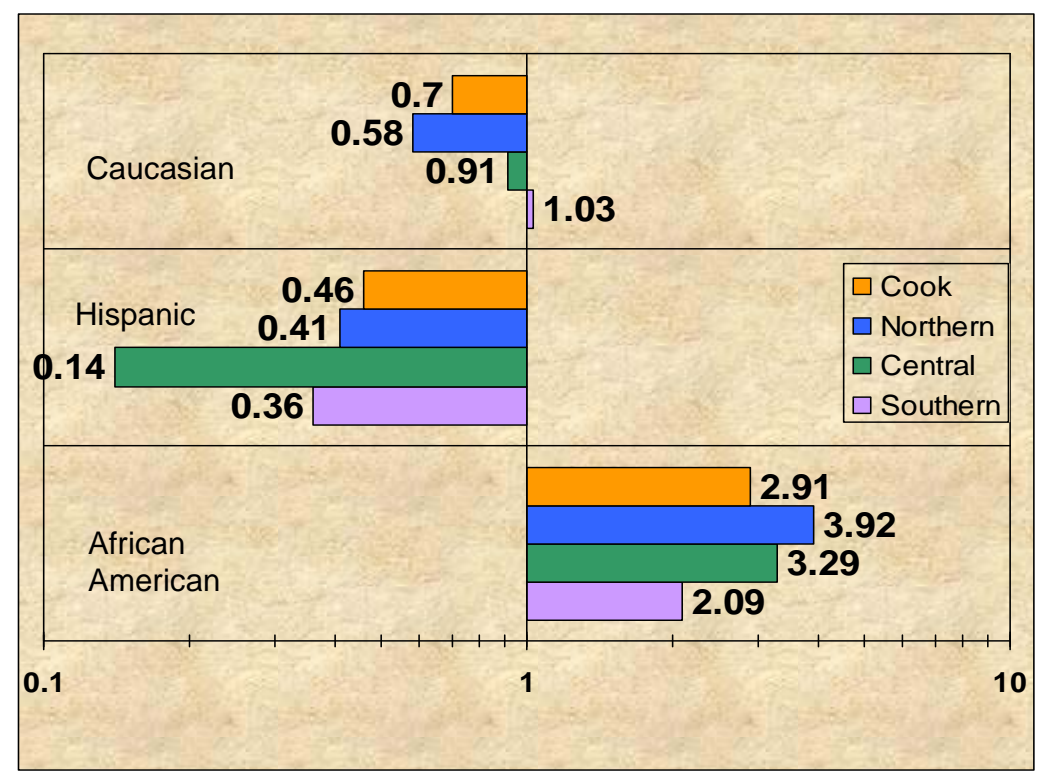

Figure 2. Maltreatment investigations relative to the total population. Weighted risk ratios are plotted for children having been investigated for a report of maltreatment compared to the composition of their racial group within the general population of Illinois. For each racial group the results are subdivided by region within the state. Values less than 1 indicate a lower incidence of investigation relative to their racial composition in the state, while values greater than 1 indicate a higher incidence.

Figures 3 and 4 show the disparity related to the decision to provide services to the child or family. In Figure 3, children investigated for maltreatment were examined to assess disparity in the decision to provide in-home (or intact family) services. The denominator was all children investigated for maltreatment and the numerator those children who received in-home services. As shown in Figure 3, the disparity at this point is not as great as that in Figure 2. African American children are underrepresented in Central and Southern regions, they are 0.85 times as 
likely to receive in-home services than all other children in the state who are subjects of a maltreatment investigation. In the Northern region and in Cook County, there is very little difference for African American children when compared to other children (0.98 and 1.01 respectively). By contrast, for children of Hispanic origin, they are 1.37 times more likely to receive in-home services than children of other ethnicities in the Central region, 1.22 times as likely in Cook County, 1.16 times as likely in the Southern region, and 1.09 times as likely in the Northern region.

Figure 3. Of all Children Investigated for Maltreatment, the Weighted Risk Ratio of Receiving At Home Services

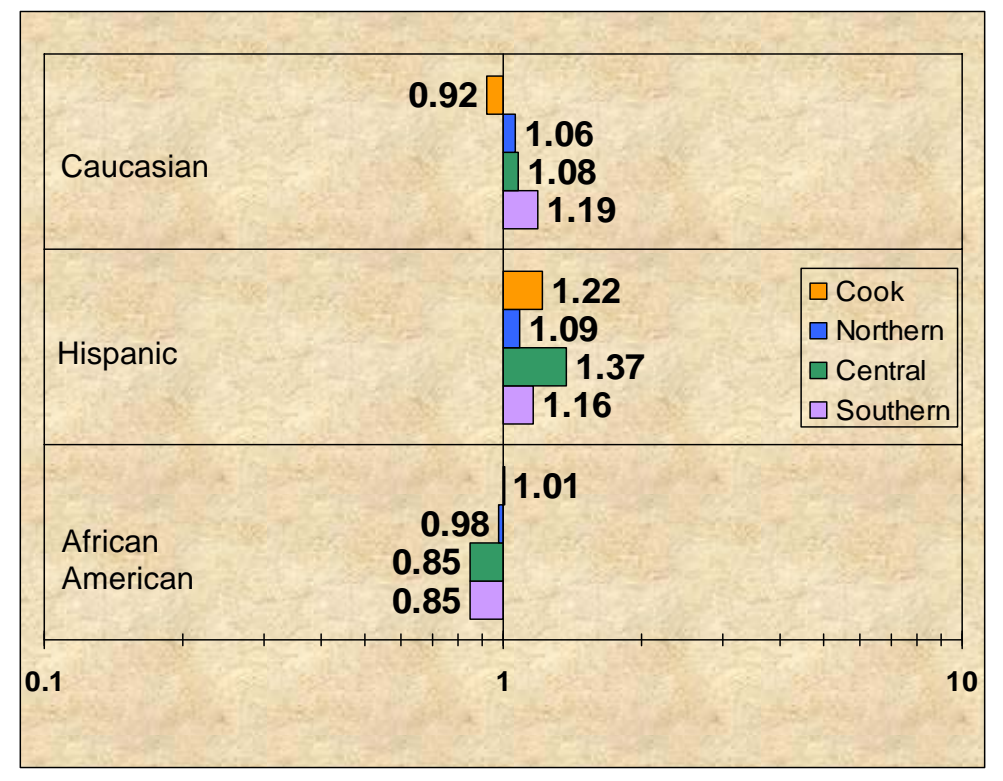

Figure 3. Receipt of at home services following a maltreatment investigation. Weighted risk ratios are plotted for children who received at home services following an investigated report of maltreatment compared to all children investigated for maltreatment. For each racial group the results are subdivided by region within the state. Values less than 1 indicate a lower likelihood for at home services relative to their racial composition in the total investigated group, while values greater than 1 indicate a higher likelihood.

Similarly, in Figure 4 the denominator is all children investigated for a report of maltreatment, but the numerator is those children who were removed from their homes and 
placed in foster care. As shown in Figure 4, there is a disparity for African American children in the rate at which they enter foster care in every region when compared to other children: African American children are 2.00 times more likely to enter foster care in Cook, 1.84 times more likely in the Northern region, 1.61 in Central region, and 1.05 times more likely in the Southern region. Hispanic children are also overrepresented in Southern (1.61) region. Children of Hispanic origin in Cook County and the Northern region are underrepresented, 0.59 and 0.49 respectively. Caucasian children are also underrepresented, in every region of the state: 0.57 in Cook County, 0.62 in Central, 0.65 in Northern and 0.84 in Southern region.

Figure 4. Of all Children Investigated for Maltreatment, the Weighted Risk Ratio of Entering Foster Care

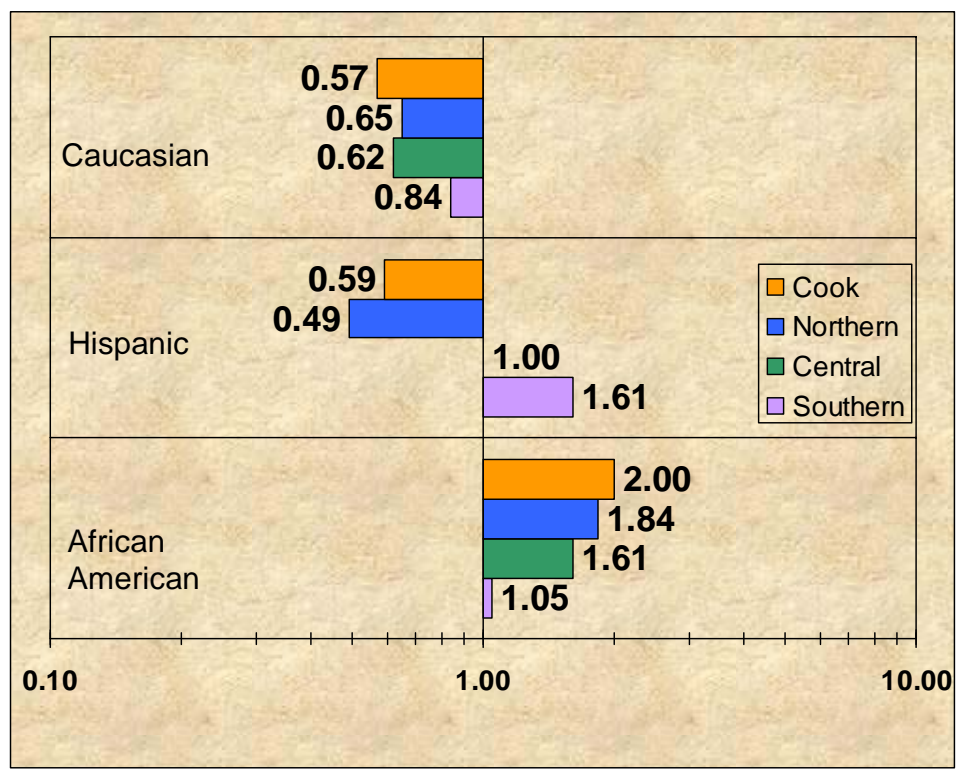

Figure 4. Children entering foster care following maltreatment investigation. Weighted risk ratios are plotted for children who enter foster care following an investigated report of maltreatment compared to all children investigated for maltreatment. For each racial group the results are subdivided by region within the state. Values less than 1 indicate a lower likelihood for entering foster care relative to their racial composition in the total investigated group, while values greater than 1 indicate a higher likelihood. 
Once a child enters foster care, child welfare systems seek to provide continuity, stability, and ultimately a permanent home for the children they serve. Each of these outcomes should be examined in a more exhaustive decision based analysis, however for this paper the disparity rates for children who do not attain permanence by their third year in care are examined. The denominator for this calculation is all children who entered foster care three years prior, and the numerator is the children who remained in foster care three years later, in other words, those children who did not exit foster care to a permanent home, through reunification, adoption or subsidized guardianship. As depicted in Figure 5, African American children are overrepresented in most regions. In the Northern region, African American children are 1.34 times as likely to remain in long term foster care, 1.23 times as likely in Central region, 1.22 times as likely in the Southern region, and no more likely in Cook County (1.01). Children of Hispanic origin are less likely to remain in long term foster care in the Northern and Central regions ( 0.40 and 0.49 respectively, slightly more likely in the Southern region (1.13), but no more likely in Cook County (0.95). Caucasian children are less likely to remain in long term foster care in most regions (0.85 in Northern, 0.82 in Southern, 0.86, and 0.90 in Central), and equally likely in Cook (1.03). 
Figure 5. Of All Children Placed in Foster Care, the Weighted Risk Ratio of Long Term Foster Care

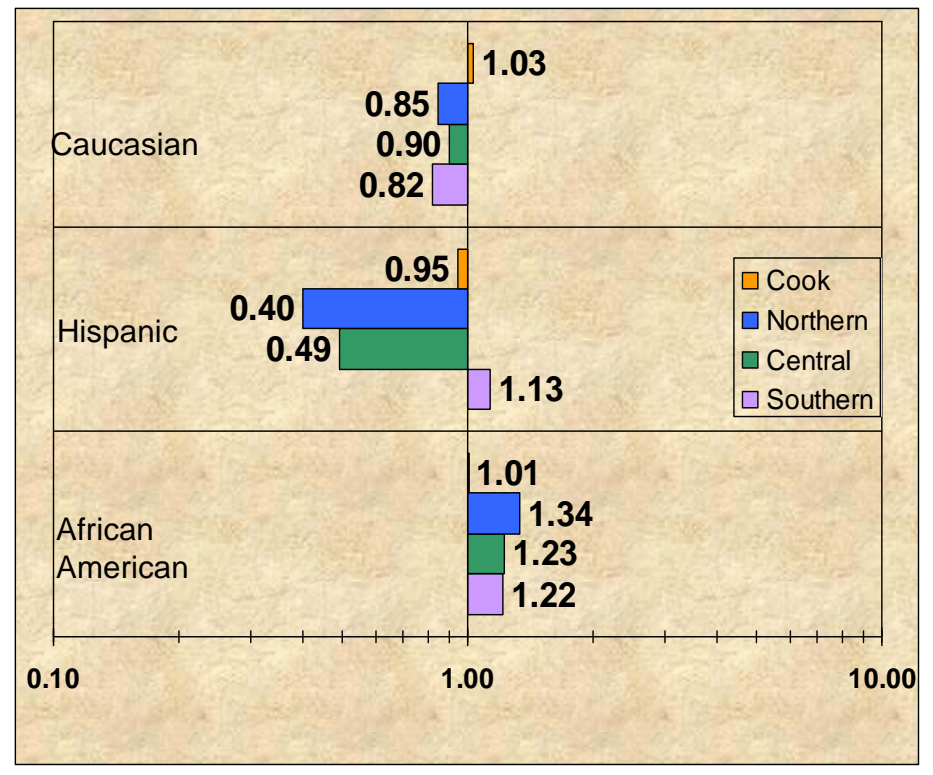

Figure 5. Children progressing to long term foster care. Weighted risk ratios are plotted for children who have progressed to long term foster care (at least three years) compared to all children who entered foster care. For each racial group the results are subdivided by region within the state. Values less than 1 indicate a lower likelihood of progressing to long term foster care relative to the racial composition of the all children entering foster care, while values greater than 1 indicate a higher likelihood.

\section{Limitations}

Decision based enumeration has not been fully explored in the literature or in discussions of measurement of disparities in child welfare. As such, there is no clear consensus on which decision points to include in an analysis of this sort. While this study provides a beginning point, additional discussion needs to occur within the field to arrive at a consensus regarding critical decision points to be included in this type of analysis. Furthermore, these calculations are based on administrative data, and one of the limits of administrative data is that child welfare agencies do not always collect the information needed to assess disparities at each decision point. 
The calculation of a weighted risk ratio provides child welfare county or state systems with ideas about where, and at what stages, disparity is the greatest, but it does not suggest how to go about addressing the issue, or if it should be addressed. Additional work needs to be done to fully understand these issues. Despite research showing the importance of how community factors, family income or structure, social supports, or other factors impact who is involved in foster care, or how decisions are made about the children and families who become involved in the child welfare system, this study does not address these issues. These factors need to be addressed in future research. Finally, these ratios do not address the human element; the use of this methodology needs to occur within context, and with consultation with the children and families most impacted by child welfare agencies should be considered in future work on evaluating disparities in child welfare decision making.

\section{Discussion}

This study examines the use of a weighted risk ratio in determining disparities within a single state. By standardizing racial or ethnic composition in a community, a weighted risk ratio produces community level disparity rates that are comparable across the state. By contrast, a risk ratio may over estimate disparities in communities with large populations of children of a particular racial or ethnic group and under estimates disparities in communities with a smaller percentage of the same racial or ethnic group. In urban settings like Chicago, for instance, where African American children make up a larger percentage of the children than in a smaller community, a weighted risk ratio takes into consideration the racial composition of children in the community in conjunction with the statewide racial composition. For states interested in determining where disparities are the greatest, a weighted risk ratio provides comparable data in each community. 
This method does not promote a standard for when an observed disparity should be of concern. Disparities can be warranted when, for instance, there are actual differences in risks and needs; disparity is of concern when it is based on bias. This method does not determine when bias exists; rather it provides a way to assess relative disparities within a state or other geographic entity. This method aims to present ratios that can be used to target policies and practices that address disparate treatment of children of color in child welfare systems. Additional research is needed to assess and address bias where it occurs.

This evaluation of the Illinois child welfare system shows that in the Northern region of the state African American children are 3.92 times as likely to be investigated for a maltreatment report, followed by Central region (3.29) and Cook County (2.91). In addition, African American children are more likely to be removed from home and enter foster care in Cook County (2.00) and in Northern (1.84) and Central (1.61) regions. Once in care African American children are more likely to remain in long term foster care, and are less likely to be attain permanence in all regions of the state (Northern region (1.34); Central region (1.23); and Southern region (1.22)). Efforts to address the disparate treatment of African American children in Illinois’ child welfare system should address these decisions points first.

As evidenced in these data, African American children enter foster care at higher rates, and exit foster care to permanence at lower rates. This disparate treatment at entry and exit results in the disproportionality observed when comparing the rate of African American child welfare involvement to the proportion of African American children living in the community. To address disproportionality, we must first address the disparate treatment of African American children and families at each decision point. Only by addressing the disparate treatment of African American children in maltreatment reporting, investigations, foster care entries, 
treatment in care, and exits from care, can we address the disproportionate involvement of African Americans children and families.

These data are descriptive and provide the beginning point for looking at disparities more thoroughly. This paper has not discussed other factors that may impact the likelihood that a child or family will come to the attention of a child welfare system, or subsequent decisions about such involvement. In addition, this study does not control for the impact of poverty, a key significant finding of the recent NIS-4 study (Sedlak et al., 2010). Other research suggests that poor children are overrepresented in the child welfare system, and that this is driven largely by the presence of increased risk among poor children that come to the attention of child welfare rather than high levels of systematic bias (Jonson-Reid, Drake \& Kohl, 2009; Drake, Lee \& Jonson-Reid, 2009). These are significant findings that need to be addressed. However, the descriptive findings in this paper illustrate a new way of measuring disparity that highlight the decision points and the communities where disparity is the greatest. Future research needs to consider incorporating additional factors into this measurement tool. A significant benefit of using a weighted risk ratio is that the underlying data is readily available and the calculation is straightforward. Using a weighted risk ratio to address the disparate treatment of children of color in the child welfare system allows child welfare professionals to assess where limited resources can be targeted to areas within their state where needs are the greatest and resources most needed. 


\section{References}

Barth, R. P. (2005). Child welfare and race: Models of disproportionality. In D. M. Derezotes, J. Poertner \& M. F. Testa (Eds.), Race matters in child welfare: The Overrepresentation of African American children in the system (pp. 25-46). Washington, DC: Child Welfare League of America.

Bartholet, E. (2009). The Racial Disproportionality Movement in Child Welfare: False Facts and Dangerous Directions. Arizona Law Review (51), 871- 932.

Bollmer, J., Bethel, J., Garrison-Mogren, R., \& Brauen, M. (2007). Using the risk ratio to assess racial/ethnic disproportionality in special education at the school-district level. Journal of Special Education, 41(3), 186-198.

Chapin Hall Center for Children. (2008). Understanding racial and ethnic disparity in child welfare and juvenile justice. Chicago: Chapin Hall Center for Children at the University of Chicago.

Coulton, C. J., Crampton, D. S., Irwin, M., Spilsbury, J. C., \& Korbin, J. E. (2007). How neighborhoods influence child maltreatment: A review of the literature and alternative pathways. Child Abuse \& Neglect, 31(11-12), 1117-1142.

Data Accountability Center. Methods for Assessing Racial/Ethnic Disproportionality in Special Education: A Technical Assistance Guide. Retrieved from: https://www.ideadata.org/docs/Disproportionality Technical Assistance Guide.pdf

Derezotes, D., Poertner, J. \& Testa, M. (2005) (Eds.). Race matters in child welfare. The overrepresentation of African American children in the system. Washington, DC: Child Welfare League of America. 
Drake, B., Lee S. M. \& Jonson-Reid, M. (2009). Race and child maltreatment reporting: Are Blacks overrepresented? Children and Youth Services Review, 31, 309-316. doi:10.1016/j.childyouth.2008.08.004

Fluke, J. D., Yuan, Y. T., Hedderson, J. \& Curtis, P. A. (2003). Disproportionate representation of race and ethnicity in child maltreatment: Investigations and victimization. Children and Youth Services Review, 25, 359-373. doi:10.1016/S0190-7409(03)00026-4

Hill, R. B. (2005). The role of race in foster care placements. In D. Derezotes, J. Poertner, \& M. F. Testa (Eds.), Race matters in child welfare. The overrepresentation of African American children in the system (pp. 187-200). Washington, DC: Child Welfare League of America.

Hill, R. B. (2006). Synthesis of research on disproportionality in child welfare: An update. Casey-CSSP Alliance for Racial Equity in Child Welfare. Retrieved from: http://cssp.org.

Hill, R. B. (2007). An analysis of racial and ethnic disproportionality and disparity at the national, state and county levels. Casey-CSSP Alliance for Racial Equity in Child Welfare. Retrieved from: http://cssp.org.

Jonson-Reid, M. Drake, B. \& Kohl, P. L. (2009). Is the overrepresentation of the poor in child welfare caseloads due to bias or need? Children and Youth Services Review, 31, 422-427. doi:10.1016/j.childyouth.2008.09.009

Lu, Y. W., Landsverk, J., Ellis-Maclead, E., Newton, R., Ganger, W., \& Johnson, I. (2004). Race, ethnicity, and case outcomes in child protective services. Children and Youth Services Review, (26), 447-461.

Methods for Assessing Racial/Ethnic Disproportionality in Special Education: A Technical Assistance Guide (2007). Retrieved from: http://www.ideadata.org/TAMaterial.asp 
Needell, B., Webster, D., Armijo, M., Lee, S., Cuccaro-Alamin, S., Shaw, T., Dawson,W., Piccus, W., Magruder, J., Exel, M., Conley, A., Smith, J. , Dunn, A., Frerer, K., \&Putnam Hornstein, E. (2010). Child Welfare Services Reports for California. Retrieved from: http://cssr.berkeley.edu/CWSCMSreports

Roberts, D. E. (2007). Toward a community-based approach to racial disproportionality. Protecting Children, 22(1), 4-9.

Sedlak, A.J., Mettenburg, J., Basena, M., Petta, I., McPherson, K., Greene, A., and Li, S. (2010). Fourth National Incidence Study of Child Abuse and Neglect (NIS-4): Report to Congress. Washington, DC: U.S. Department of Health and Human Services, Administration for Children and Families.

Shaw, T. V., Putnam-Hornstein, E., Magruder, J., \& Needell, B. (2008). Measuring Racial Disparity in Child Welfare. Child Welfare, 87(2), 23-36.

Wulczyn, F., \& Lery, B. (2007). Racial Disparity in Foster Care Admissions. Chapin Hall: University of Chicago.

Wulczyn, F., Lery, B., \& Haight, J. (2006). Entry and Exit Disparities in the Tennessee Foster Care System. Chapin Hall Discussion Paper.

U.S. Department of Health and Human Services, Administration for Children and Families, Administration on Children, Youth and Families, Children’s Bureau. (2005). Child Welfare Outcomes 2002-2005: Report to Congress. Washington, DC: Government Printing Office. Retrieved from http://www.acf.hhs.gov/programs/cb/pubs/cwo05/index.htm

U.S. Department of Health and Human Services, Administration for Children and Families, Administration on Children, Youth and Families, Children's Bureau. (2010). AFCARS 
Report - Preliminary FY 2009 Estimates as of July 2010 (17) Washington, DC:

Government Printing Office. Retrieved from

http://www.acf.hhs.gov/programs/cb/stats_research/afcars/tar/report17.htm

United States Government Accountability Office. (2007). African American Children in Foster

Care: Additional HHS Assistance Needed to Help States Reduce the Proportion in Care.

Retrieved from http://www.gao.gov/new.items/d07816.pdf 